Julio Cesar dos Santos

\title{
A Imagem de Deus no Ser Humano, Segundo a Teologia de Emil Brunner: Um ser relacional e responsável diante de Deus
}

\section{DISSERTAÇÃO DE MESTRADO}

\section{DEPARTAMENTO DE TEOLOGIA \\ Programa de Pós-Graduação em Teologia}




\title{
Pontifícia Universidade Católica $_{\text {a }}$

Julio Cesar dos Santos

\begin{abstract}
A Imagem de Deus no Ser
Humano, Segundo a Teologia de Emil Brunner:

Um ser relacional e responsável diante de Deus
\end{abstract}

\section{Dissertação de Mestrado}

Dissertação apresentada como requisito parcial para obtenção do grau de Mestre pelo Programa de Pósgraduação em Teologia do Departamento de Teologia do Centro de Teologia e Ciências Humanas da PUC-Rio.

Orientador: Prof. Abimar Oliveira de Moraes

Rio de Janeiro

Agosto de 2009 


\section{Julio Cesar dos Santos}

\section{A Imagem de Deus no Ser Humano, Segundo a Teologia de Emil Brunner: Um ser relacional e responsável diante de Deus}

Dissertação apresentada como requisito parcial para obtenção do grau de Mestre pelo Programa de PósGraduação em Teologia do Departamento de Teologia do Centro de Teologia e Ciências Humanas da PUC-Rio. Aprovada pela comissão examinadora abaixo assinada.

Prof. Abimar Oliveira de Moraes Orientador Departamento de Teologia - PUC - Rio

Prof. Mário de França Miranda Departamento de Teologia - PUC - Rio

Prof. Nelson Célio de Mesquita Rocha Faculdade Evangélica de Tecnologia, Ciência e Biotecnologia da CGADB

Prof. Paulo Fernando Carneiro de Andrade Coordenador Setorial de Pós-Graduação e Pesquisa do Centro de Teologia e Ciências Humanas 
Todos os direitos reservados. É proibida a reprodução total ou parcial do trabalho sem autorização da universidade, do autor e do orientador.

\section{Julio Cesar dos Santos}

Graduou-se em Teologia pelo Seminário Teológico Batista do Sul do Brasil em 2005. Participou de vários congressos de Teologia ao redor do Brasil. É pastor da Igreja Batista .

Ficha Cartográfica

Santos, Julio Cesar dos

A imagem de Deus no ser humano, segundo a teologia de Emil Brunner : um ser relacional e responsável diante de Deus / Julio Cesar dos Santos ; orientadora: Abimar Oliveira de Moraes 2009.

$126 \mathrm{f}$; $; 30 \mathrm{~cm}$

Dissertação (Mestrado em Teologia)-Pontifícia Universidade Católica do Rio de Janeiro, Rio de Janeiro, 2009.

Inclui bibliografia

Teologia. III1. Teologia - Teses. 2. Imagem de Deus. 3. Revelação. 4. Responsabilidade. 5. Restauração. 6. Amor de Deus. 7. Pecado. 8. Existência humana. I. Moraes, Abimar Oliveira de. II. Pontifícia Universidade Católica do Rio de Janeiro. Departamento de. Título. 


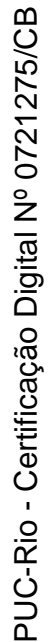

Para Marisol, verdadeira companheira. Pela paciência e ajuda ao longo da caminhada. 


\section{Agradecimentos}

Ao meu orientador Professor Abimar Oliveira de Moraes pelas orientações na realização deste trabalho.

Ao CNPq e à PUC-Rio pelos auxílios concedidos para a realização desta pesquisa.

Ao meu Professor Mario de França Miranda, que com sua paixão no ensino me levou ao tema teológico ora tratado.

A todos os meus demais professores no curso de Pós-garduação pelos constantes estímulos para a pesquisa.

Ao meu sogro e sogra, pois foram verdadeiros pais de meus filhos nos momentos de minha ausência. 


\section{Resumo}

Santos, Julio Cesar dos; Moraes, Abimar oliveira de. A Imagem de Deus no Ser Humano, Segundo a Teologia de Emil Brunner: Um ser relacional e responsável diante de Deus. Rio de Janeiro, 2009. 126p. Dissertação de Mestrado - Departamento de Teologia, Pontifícia Universidade Católica do Rio de Janeiro.

O ser humano é incontestavelmente um ser que se destaca dos demais tipos de vida existentes na terra. O teólogo suíço Emil Brunner entende este diferencial da dignidade humana a partir da compreensão teológica de que o ser humano foi criado segundo a Imagem de Deus. Mesmo diante da maldade humana, ainda assim, o ser humano é reconhecido pela teologia cristã como alguém que está em relação com Deus, por isso é responsável. São nestas duas características humanas que Brunner enxerga os traços da Imagem de Deus na existência humana. Pois somente um ser que é relacional (portanto livre e sujeito) e responsável pode ser um interlocutor de Deus, e assim ser capaz de receber e transmitir o amor que procede de Deus. Mas o ser humano pecador vive mal a sua relação e responsabilidade, pois encontra-se em um estado de pecado, que é rebelião e inimizade contra Deus. Em Jesus Cristo o ser humano tem restaurada a sua relação e responsabilidade com Deus, a Imagem de Deus é restaurada à situação que Deus quer que ela esteja. Sendo assim, nesta dissertação tratamos da teologia brunneriana em sua compreensão sobre a Imagem de Deus no ser humano antes do pecado, no estado de pecado, e à luz da revelação de Jesus Cristo.

\section{Palavras-chave}

Imagem de Deus; relação; responsabilidade; restauração; Amor de Deus; pecado; existência humana; Revelação. 


\section{Abstract}

Santos, Julio Cesar dos; Moraes, Abimar oliveira de (Advisor). The God's Image in the Human Being, According to Emil Brunner's Theology: The human being as a relational and responsible in the face of God. Rio de Janeiro 2009. 126p. MSc. Dissertation - Departamento de Teologia, Pontifícia Universidade Católica do Rio de Janeiro.

The human being is clearly a being that stands out from other types of life existing on earth. The Swiss theologian Emil Brunner understands this human dignity differential from the theological comprehension that the human being was created according to God`s Image. Even in the face of human evil, the human being is recognized by the Christian theology as someone who is in relation with God, for this reason he is responsible. These are two human characteristics that Brunner sees traces of the God`s image in human existence. Because only a being that is relational (i.e. subject and free) and responsible can be God`s interlocutor and thus be able to receive and transmit the love that comes from God, But the sinful human being lives badly its relationship and responsibility because it is in a state of sin, which is rebellion and enmity against God. In Jesus Christ the human being has restored its relationship and responsibility to God, the God`s Image is restored to the situation that God wants. Thus, this dissertation deals of the brunneriana`s theology in his understanding on God's image in man before the sin, the state of sin and over the light of Jesus Christ`s revelation.

\section{Keywords}

God`s Image; relation; responsibility; restoration; God`s love; sin; human existence; Revelation. 


\section{SUMÁRIO}

1. Introdução

2. O ser humano como Imagem de Deus antes do pecado 13

2.1. A questão da origem do ser humano 13

$\begin{array}{ll}\text { 2.1.1. A doutrina do estado primitivo. } & 14\end{array}$

2.1.2. O entendimento da criação do ser humano a

$\begin{array}{ll}\text { partir do Novo Testamento } & 17\end{array}$

2.1.3. O ser humano criado antes do pecado 20

2.2. Criado para responder ao amor de Deus livremente 27

2.2.1. Entendendo a liberdade do ser humano na criação 28

2.2.2. A vontade de Deus para o ser humano 30

2.2.3. O ser humano como uma criatura frágil 33

3. A Imagem de Deus no ser humano pecador 37

3.1. Caminho para uma "doutrina bíblica" do pecado 38

3.2. O ser humano em estado de pecado 43

3.2.1. A integralidade do estado de pecado do ser humano 47

3.2.2. O pecado como rebelião à dependência de Deus 48

3.2.3. O pecado como um elemento universal 52

3.2.3.1. A solidariedade do pecado entre os seres humanos 52

3.2.3.2. A solidariedade do pecado no tempo 55

3.3. A Imagem de Deus como algo inerente ao ser humano 57

3.3.1. A Imagem de Deus no ser humano em seu aspecto formal 58

3.3.2. O ser humano como sujeito 61

3.3.3. O ser humano como ser relacional 64

3.3.4 - O ser humano como ser de responsabilidade 66

3.3.5. A importância da analogia entis na compreensão antropológica 68

4. A Imagem de Deus no ser humano no evento Jesus Cristo 74

4.1. A Imagem de Deus no ser humano em seu aspecto material 74 
4.2. A Importância histórica do evento Jesus Cristo 80

4.2.1. A salvação como um momento específico da história 81

4.2.2. O ser humano chamado para uma Aliança com Deus 88

4.2.2.1. Sentido negativo da Lei 90

4.2.2.2. Sentido positivo da Lei e sua conexão com Jesus Cristo 93

4.2.3. A "plenitude dos tempos" 98

4.3. A obra salvífica de Deus em Jesus Cristo 102

4.3.1. O ofício profético de Jesus Cristo 103

4.3.2. A obra sacerdotal de Jesus Cristo 108

4.3.3. A obra real de Jesus Cristo 115

4.4. O ser humano restaurado por Jesus Cristo 118

$\begin{array}{lll}\text { 5. Conclusão } & 121\end{array}$

6. Referências bibliográficas 123 